\title{
O AUTO-RETRATO COMO CONSCIÊNCIA DA NOSSA VIDA
}

\author{
José Artur Ramos \\ (Faculdade de Belas-Artes, Universidade de Lisboa)
}

A representação gráfica ou pictórica de um objecto que visa uma aproximação objectiva exige um intenso trabalho de observação do modelo, a fim de se tentar compreender as suas particularidades formais. Considera-se em grande parte que o tempo concedido à observação condiciona o sucesso da representação. Esta tarefa pode ser facilitada se o modelo for um objecto simples ou não orgânico, pois nesse caso ele permite o acesso a uma estrutura fixa que passa por uma visualização da sua geometria dentro de esquemas de construção, como a perspectiva linear, ou outros tão rigorosos quanto matemáticos. No entanto, se devido à sua natureza, o objecto estiver sujeito a alterações que se manifestem na sua forma, então surgem problemas que comprometem toda a observação e por conseguinte o resultado final. Em relação ao corpo humano e especificamente ao rosto, que possui esta característica de mutação, existe sempre a possibilidade de se aplicar esquemas anatómicos e fisionómicos que, aliados a certos ideais, o defendem dessas variações.

Contudo, se considerarmos o nosso próprio rosto, que é aquele que está mais perto de nós e que constantemente apresenta com clareza essas variações, então elas mesmas podem-se tornar no próprio caminho para a sua representação. Isto é, trata-se de compreender essas variações no sentido de as poder representar em articulação com outros factores de mudança, cujas intervenções são tão específicas e também tão simples que a sua enunciação por palavras se torna uma tarefa difícil, mas que pelo desenho ou pela pintura se tornam visíveis.

De todas estas variações, aquelas que agora nos interessam estão estreitamente ligadas ao factor tempo, não só compreendido no auto-retrato isolado, quando este é executado num determinado espaço de tempo da vida do artista, mas também na própria sequência de retratos executados 
ao longo da vida. De facto, existem variações que se reflectem no rosto e que são provocadas por expressões de sentimentos ou estados emocionais e pelas condições atmosféricas relacionadas com a natureza da luz e da cor ambiente, que produzem efeitos particularmente transformadores do rosto. Por outro lado, o grau de consciência dessas variações depende também das determinações da nossa realidade subjectiva que fazem com que a nossa visão esteja de dia para dia mais ou menos desanuviada de dúvidas, e ainda do ânimo mais ou menos caprichoso da nossa vontade. Mas o que caracteriza estas variáveis e que está para além delas, é o facto de possuírem todas um denominador comum responsável pela sua ocorrência, isto é, o binómio movimento e tempo.

Assim a integração destes factores como matéria fundamental do auto-retrato, caracteriza, como iremos demonstrar, não somente a fisionomia particular de cada um ou um estado de alma mais particular, mas sobretudo a auto-identificação da vida de um homem que se assume na sua totalidade como indivíduo e que acaba por estar para além da dualidade corpo/alma e das vicissitudes das suas paixões. Como exemplo emblemático deste modo de aproximação ao auto-retrato podemos destacar Rembrandt, não só pelos inúmeros auto-retratos que fez ao longo da sua vida, mas também pelo próprio processo de representação plástica do rosto.

Georg Simmel, na sua obra Rembrandt, de 1916, expõe uma concepção de vida segundo a qual a expressão teórica de Rembrandt está condicionada. Porém, esta concepção não se cinge apenas a Rembrandt, embora este seja uma referência, visto que se torna mais presente à medida que nos aproximamos dos dias de hoje, através de trabalhos que chegam a ultrapassar o domínio da pintura. Essa concepção reflecte a influência de Henri Bergson enquanto encara a vida como um fluxo contínuo. A vida não é constituída pela soma de uma série de instantes que emergem sucessivamente, uma vez que essa soma não nos permite sentir a vida na sua unidade e totalidade. Pelo contrário, a vida é "uma unidade em si, mas uma unidade que se manifesta em cada instante como sendo total e com uma forma diferente." Portanto, esta unidade engloba vários momentos puramente qualitativos ou distintos pelo seu conteúdo, que se estendem desde o passado até ao presente e onde, como Simmel afirma: "cada momento actual determinado pelo curso inteiro da vida anterior, é o resultado de todos os momentos passados e, por isso, o presente actual da vida é a forma em que a vida inteira do sujeito é real." ${ }^{2}$ Ou seja, "cada instante da vida é a vida inteira cujo constante fluir alcança a sua realidade."3

\footnotetext{
${ }^{1}$ Georg Simmel, Rembrandt, Ein Kunstphilosophischer Versuch (1916), trad. Emilio Estiu, Murcia, Librería Yerba Cajamurcia,1996, p.9.

${ }^{2}$ Ibid., p. 9.

${ }^{3}$ Ibid.
} 
Deste modo, cada momento da vida parece conter um passado de momentos que por sua vez o condicionam. É possível que na construção do auto-retrato se consiga captar o momento exposto que intuitivamente parece abarcar todo o impulso que vitalmente aponta para ele. Desta maneira, cada quadro narra a história dessa corrente vital. Esta posição perante a corrente da vida destaca-se daquele modo de registar o momento do acontecimento em que o instante aparece subtraído e cristalizado, assumindo-se como forma autónoma. O processo segundo o qual Rembrandt representa o homem nos seus retratos e auto-retratos deixa, segundo Simmel, transparecer esses momentos não numa totalidade de vários instantes, porque a forma não está dada toda por igual em termos de detalhe, nem está toda acabada por igual, nem toda parece estar definitivamente no seu correcto lugar, mas numa "corrente contínua que continuamente vai mudando de forma" ${ }^{4}$. Assim, demonstra intuitivamente que cada instante exposto não é um estado fixo. Existe qualquer coisa que nele se move e o anima, qualquer força que possui a essência da vida.

$\mathrm{O}$ retrato clássico exclui esse momento de devir, porque encerra $\mathrm{o}$ retratado no instante do seu presente, tornando-o fechado ${ }^{5}$ à essência qualitativa e intemporal do indivíduo, uma vez que os seus traços fisionómicos e a sua pose são subordinados a uma fixa configuração. Nestes casos, como Simmel defende: "a alma, segundo a sua real particularidade, determina a forma e não se alcança senão através de uma abstracção intuitiva em que as determinações se oferecem numa essência intemporal." ${ }^{\prime 6}$ Por conseguinte e quase que de um modo oposto, pode-se trabalhar a fisionomia de forma a revelar aquilo que anima o corpo sem o submeter a categorias e esquemas de construção que se pretendem universais. Procuramos assim, através da imagem, uma força que se revela no curso vital de um momento presente que deixa visível todo o percurso que nos leva até ela. Esta força anímica manifesta-se na mobilidade da vida que por sua vez se revela na constante presença do instante.

Sabemos que a exposição numa imagem fixa e exterior, como a pictórica, de algo que por um lado se dá apenas na sequência temporal e que por outro se anima interiormente, levanta problemas óbvios. Mas, estes são para Simmel ultrapassados quando se consegue evitar subtrair os

${ }^{4}$ Ibid., p. 10.

${ }^{5}$ Os conceitos de forma fechada e forma aberta usados por Simmel reflectem a directa influência das teorias de Henrich Wölfflin, desenvolvidas nomeadamente em Kunstgeschichtliche Grundbegriffe. Das Problem der Stilentwicklung in der Neueren Kunst, trad. João Azenha, Conceitos Fundamentais da História da Arte. $O$ Problema da Evolução dos Estilos na Arte Mais Recente, São Paulo, Martins Fontes, 1996.

${ }^{6}$ Georg Simmel, op. cit., pp. 14-15. 
elementos da imediatez do seu ser vivido, quando se capta a variação e se mostra todos os degraus numa acumulação de momentos que conservam a sua ordem histórica, sem se abstrair dos momentos singulares da sua vida. Este processo confere ao homem na sua singularidade a ideia de universalidade ao incluir, de um modo muito próximo de nós, a ideia de mobilidade da vida ou de animismo.

Não queremos com isto dizer que aos retratos clássicos falte vida $\mathrm{e}$ alma. Estas também estão presentes só que dotadas de uma forma universal, onde se revela tão perfeita que só se dá à disposição da mobilidade psíquica dos seus resultados. É uma certa universalidade que não distingue os conteúdos das diferenças individuais e por isso apresenta o indivíduo ideal, podendo provocar uma interferência no próprio processo e representação exactamente pelo risco de solidificar a vida num só momento, tornando a configuração demasiado concentrada. Portanto, é um processo que ultrapassa a variação, o pormenor e o efémero. Não promove a possibilidade de o artista se confrontar com esses aspectos que são distinguidos tanto na vida real como nos meandros das etapas da representação pictórica. Porque a atenção que o retratar requer assenta exactamente neste confronto que deve então surgir de um modo fluente onde, a cada instante, a configuração observada se dilui para se refazer pelas suas partes, pelos detalhes mais singulares ou particulares e sempre diferentes de momento a momento e de quadro para quadro.

Esta atitude perante a vida e o retrato, constitui uma referência e um ponto de partida que Simmel encontra em Rembrandt e que se mantém até aos nossos dias. Não podemos afirmar que é o único, mas antes um caminho possível para a representação da totalidade humana viva. Nesse processo da construção do auto-retrato, o desenho marca a sua intervenção quer pela actuação directa na própria superfície pictórica, quer pela possibilidade de constituir um estudo prévio perante a própria execução pictórica. Tanto num caso como no outro, o desenho apresenta a capacidade de analisar a realidade de um modo espontâneo e imediato, que geralmente a pintura não possui. Esta característica específica de uma das várias áreas do desenho - a representação de um modelo vivo - pode significar que esse apontamento gráfico se circunscreve demasiado num espaço de tempo, e por isso pode impor uma representação solidificada de um momento, com todas as contrariedades atrás expostas. No entanto, o desenho não deixa de conferir ao processo uma continuidade do fluir próprio de cada acto da nossa vida, desde que não feche a forma nem a sujeite a um modelo ou esquema anatómico previamente perfeito. Porque o desenho pode também ser um instrumento de auscultação que enquadra o pormenor, a variação, a incerteza e o adiado que será refeito ou diluído mais tarde.

Queremos assim dizer que este processo leva o artista a "procurar desde de baixo, desde aquilo que em comparação com a forma existente é 
completamente informe e obscuro.."7 Passa-se aqui de certo modo o contrário do que acontece com a teoria da ideia que procura adequar aquilo que vê a algo já configurado e que é procurado a partir de cima ${ }^{8}$, utilizando uma expressão de Simmel. Ou por outras palavras, não se trata de configurar o modelo a um esquema preestabelecido onde os elementos anatómicos são submetidos a uma estrutura fixa que enfatiza certas expressões formais, nem tão pouco se pretende captar todos os traços vistos em singular e na mesma sucessão. Mas, pelo contrário, trata-se de reduzir a aparência do retratado a uma intuição essencial, que implica introduzir uma certa distância entre nós e a fixa exterioridade do modelo, a fim de libertar as suas formas através da sua extensão no tempo e no espaço. Esta extensão refere-se à construção da forma a partir das suas partes que ganham unidade ao longo de todo o seu crescimento, visto que toda a obra de arte possui uma extensão no espaço e no tempo. Assim, compreendemos que o artista recrie o fenómeno ao fazê-lo crescer de baixo, como Simmel defende a propósito de Rembrandt, onde:

o decisivo é antes de tudo, aquela recriação de dentro para fora, o 'Morre e transforma-te' ['Stirb und werde'] do fenómeno, os dois termos entre os quais reside o submergir naquele momento de fecundação em si unitário e tão encoberto como o próprio surgimento de uma vida. ${ }^{9}$

Vimos como é possível o retrato afirmar, pela forma como se derrama na continuidade da vida, a individualidade do homem. Por conseguinte, temos que aceitar a ideia de que o retrato pode deixar transparecer a visibilidade do passado na imagem presente do homem. Como a sua alma ou a sua força anímica deixa-se dar no instante presente da corporalidade. Então, também o passado, que se desenvolve até constituir a actualidade, se pode projectar no retrato. Ora, este círculo segundo o qual compreendemos o passado a partir do presente, é o único raciocínio que se nos apresenta, uma vez que ele só pode derivar a partir do presente. Assim, partindo do próprio presente sensível onde mediante um procedimento intelectual reconstruímos o passado, podemos então ultrapassar a mera e directa representação dada no momento presente ${ }^{10}$. Isto é, acreditamos que sobre a aparência do presente é derramada sem pausas a corrente contínua da vida, visto que o homem é uma totalidade que ultrapassa o momento presente, pois é algo que em si está para além dessa oposição entre passado e presente.

\footnotetext{
${ }^{7}$ Ibid., p. 49.

${ }^{8}$ Ibid.

${ }^{9}$ Ibid., p. 52.

${ }^{10}$ Ibid.
} 
Consideramos que o auto-retrato é por excelência feito de momentos que se estendem, o que permite ao artista aperceber-se dessa evolução ou continuidade na forma observada e no que a comparação dela com o representado possui de diferente, porque é um produto de visões separadas temporalmente. O rosto, na sua forma exterior, é de facto sujeito às variações que se dão no tempo e na vida. Com o tempo e o decorrer dos seus momentos, a forma vai sendo sacrificada ultrapassando a imagem objectiva por antecipação, isto é, vai-se instalando na tensão da imagem no seu nascer. A forma nunca chega a ser completamente fechada, como acontece nos quadros do Renascimento, pois tudo fica em suspenso e em tensão, pois nada se fixa ao instante em que a forma se dá no seu carácter fechado, isto é, linearmente concluída.

Esta suspensão da forma que parece adiar o seu desenvolvimento, ganha mais legitimidade quando se trata de um auto-retrato, quando se parte de si e estando para lá do exterior reflectido, a visão molda-se a esse curso para penetrar e adaptar o exterior. A um curso que traz para o presente o passado em função da sua forma que viu viver e da memória desses instantes em que nunca nada é definitivo mas que constantemente se refaz num agora. É um constante chegar a uma representação que é constituída a partir de um agora já dado, já sido ou visto anteriormente. É como que uma sequência de quadros fixos do visto que se dá nesse agora, e que parece tornar impossível cristalizar numa imagem objectiva pois falta-lhe sempre a repetição no tempo que existiria num a seguir que parece não chegar. No entanto, quando conseguimos intuir esse agora, então vemos claramente a vida representada.

$\mathrm{Na}$ verdade, o presente do quadro não possui apenas um instante, ele lança-nos num passado que se torna cada vez mais presente, até o ser. É um acontecimento gerado por um corpo que não está fixo ou que não está petrificado. Pelo contrário, ele mexe-se, actua e vive. Neste sentido, compreendemos que como em qualquer ser vivo existe um ânimo que podemos designar por alma. E esta revela-se pelo corpo, e não existe numa oposição ao corpo, como certas teorias defendem. Não se trata, de facto, de estabelecer uma luta entre a alma e o corpo em que uma delas se submete à outra, ou que ambas existem numa permanente dualidade e tensão, como acontece no retrato que se submete a um tipo onde o exterior da forma está configurada à interioridade da alma. Daí que o artista, como diz Simmel a propósito de Rembrandt, "não concebe o corpo e a alma numa interacção onde cada um seria um meio para a exposição ou interpretação do outro, mas concebe a totalidade do homem, a qual não significa a síntese do corpo e alma mas sim a sua inseparabilidade." 11

${ }^{11}$ Ibid., p. 33. 
Por conseguinte, nessa totalidade manifesta-se a interioridade e a exterioridade impossíveis de se pensarem separadamente. E é a natureza desta relação que nos leva a compreender aquilo que determina a animosidade. Esta experiência é constante, e quanto mais a percebemos, mais é acentuada a sua individualidade. Neste sentido, o auto-retrato surge com uma conduta que o distancia do retrato, visto que "a realidade exterior do modelo vidente e a realidade ditada desde dentro do artista estão na sua consciência como unidade" ${ }^{12}$. Isto é, perante o retrato de alguém é mais difícil aceder àquilo que é mais intenso e específico. Chegar pelos seus traços ao seu carácter, no sentido em que se pode produzir opinião sobre a sua natureza, pouco adianta em termos de alma e apresenta-se como um caminho difícil. Porque, nestes casos, a configuração do retratado é determinada pela personalidade do artista naquilo que ela tem de subjectivo, uma vez que a obra de arte é uma objectivação do sujeito enquanto autor.

Todavia, quando se trata do auto-retrato, tudo nasce duplamente de dentro sem haver oposição entre o corpo e a alma. E é nesse sentido que Simmel afirma ser o auto-retrato a escola e de certo modo o protótipo em que os opostos não se dissociam ${ }^{13}$. De facto, no auto-retrato a possibilidade desse conhecimento intuitivo de si pode estar presente com acuidade ou legitimidade e orienta, por sua vez, todo esse conhecimento para o essencial. A inseparabilidade entre corpo e alma, ou seja, a unidade do exterior e interior, apresenta-se através da continuidade da vida que a experiência do auto-retrato proporciona ao autor. Ela vai passando de obra para obra em renovados e, neste caso, em reavivados auto-retratos como tentativa de conseguir desse modo a fórmula universal da unidade.

No entanto, podemos admitir esta ideia de inseparabilidade porque existe a possibilidade da imagem conseguir transmitir a percepção desse ânimo, apesar de esta só se unir e se revelar na realidade vivente com o corpo. Portanto no auto-retrato não existe nenhuma adversidade entre a possibilidade criadora e a representada, pois elas são a mesma.

$\mathrm{O}$ auto-retrato como representação de um sujeito encerra em si a possibilidade de transmitir aquilo que ele tem de único enquanto indivíduo. Este conceito de individualidade que Simmel expõe, não está ligado a determinadas posições racionalistas ou mecanicistas. Por exemplo, aqueles modos segundo os quais se submete o homem a conceitos psicológicos, de boa ou má personalidade, não permitem que o nosso conhecimento sobre a alma se amplie. Porque não conhecemos o homem 'desde dentro' visto que o conhecimento flui do conceito que transportamos connosco. Por outro lado, o modo como conhecemos o homem depende das circunstâncias da vida exterior. Ora a sua posição social, estado civil,

\footnotetext{
${ }^{12}$ Ibid., p. 46.

${ }^{13}$ Cfr. ibid., p. 46.
} 
riqueza ou pobreza não o relacionam com aquilo que ele tem de único e universal enquanto indivíduo, elas são apenas circunstâncias da vida exterior. Aqui não conhecemos o homem verdadeiramente, isto é, 'desde dentro', porque o nosso conhecimento é construído a partir de conceitos que dependem da nossa experiência em termos sociais. De resto, nenhum destes conhecimentos sobre a personalidade faz com que o conhecimento sobre a alma se amplie, nem com que se revele o que nele há de mais universal enquanto indivíduo.

Assim, o homem é visto intuitivamente numa totalidade que coincide com o percurso total do seu destino. Esta totalidade é o individual. A fim de explicar esta ideia, Simmel compara-a com o que acontece nos retratos clássicos. Estes concebem o homem como um tipo ou como uma multiplicidade de universalidades. $O$ contemplador não atinge o retratado de modo a fundir-se ou a identificar-se sentimentalmente com ele, porque a sua totalidade encontra-se numa configuração universal adaptável às diversas aparências. Os traços do retratado são subordinados ao princípio da forma pura, isto é, são colocadas num plano de igualdade as diversas aparências dos elementos da superfície. Portanto, para compreendermos este conceito de individualidade, é preciso um caminho e um fim que não coincida com o tipo a que o retrato clássico nos habituou.

O devir é deixado para trás de si, e a forma adquire uma essência supra-individual. $\mathrm{O}$ carácter do típico que caracteriza o retrato clássico apresenta uma uniformidade no tratamento dos rostos transportando-os para uma vida superior ou paralela à nossa: "Assim, como o conceito universal se comporta com respeito ao singular que está por debaixo dele, a forma relaciona-se com a multiplicidade das existências materiais que ao entrar com todas as suas diversidades nela as configura em igualdade. ${ }^{14}$ É, de facto, uma construção que parte fundamentalmente da forma e da matéria como puro material, opondo-se ao princípio da vida tornando a forma abstracta e universal.

Ora, segundo Simmel, existe uma atitude possível que, como Rembrandt, torna a vida como um princípio condutor e o caminho que segue em direcção à universalidade é o inverso do anterior, pois a vida vincula-se à configuração individual. Neste sentido, cada indivíduo tem a sua vida que lhe dá a forma em sim mesmo. Porque pela vida revela-se, primeiro de tudo, a existência e só depois a forma. A vida é real e tem por isso, em cada uma das suas séries, aquela individualidade que possui cada fragmento da sua existência por ser realidade.

Todavia, quando conhecemos um homem, no primeiro instante não temos acesso a essas características expostas. Conhecemos aquilo que ele é mesmo, o corporalmente inconfundível. Depois deste primeiro momen-

14 Ibid., p. 114. 
to, existe uma contínua evolução que se enlaça e permanece ao lado desse instante. Esta evolução compreende outras séries de conhecimento que se referem às qualidades singularmente designadas. De onde se segue que o homem é um indivíduo que não está composto pela soma das suas qualidades numeráveis num dado momento, mas sim por uma continuidade de conteúdos singulares não diferenciáveis qualitativamente. Para tal conhecimento é preciso, segundo Simmel, um "órgão especial"15 que está muito desenvolvido em Rembrandt, uma vez que os seus auto-retratos representam o conhecimento de uma individualidade sentida individualmente no próprio processo da vida, no acontecer de um instante irreversível, isto é, como unidade da sua existência.

A representação desta individualidade é tomada da corrente da vida, e por isso está impregnada dela. A vida é uma ordenação na qual se acentua o facto principal e a partir deste os mais variados factos acessórios ${ }^{16}$. É composta por um ponto central seguido por uma gradação até à periferia. Então, como na vida, existe na imagem um facto principal e uma gradação própria de uma aproximação à vida que contrasta com o equilíbrio artificial e por isso se afasta das regras. A figura desenvolve-se de um centro que é um ponto superior e amplia-se pelo resto do quadro. Ela não está isolada mas sim cercada e misturada num fundo, numa paisagem, por um certo ar, luz, ou determinadas cores. Do rosto, como ponto central, irradia o fundo. Falamos aqui da individualidade da forma como um todo, de todo o quadro, dada por todas as partes do quadro onde estas ganham sentido e existência enquanto possuem uma relação com esse centro, pois o fundo é o campo onde o corpo se vê ampliado. Para tal, evita-se o detalhe mais rigoroso, procura-se a perda dos limites e dos contornos mais agudos que dividem e separam as partes da sua existência singular, porque como a individualidade é tomada da corrente da vida, elas devem-se partilhar mutuamente, como um todo. Portanto, é preciso considerar a individualidade a 'partir de dentro', para ver a sua vitalidade que determina o detalhe mas também o anula. Apresenta-se assim uma existência que se destaca do exterior para se assumir como plena individualidade. A vida individual torna-se mais palpável quanto mais os seus limites surgem independentes, isto é, quando submetem o seu contorno ao pormenor, à forma fixa e ao todo.

Esta forma, que faz a vida revelar-se, vê a sua relação com o indivíduo acentuada com a presença de um elemento aparentemente estranho: a morte. De facto, a vida de um homem que transcende o tempo aponta para um destino incontornável, "num ponto do futuro que faz em geral da vida uma totalidade justamente ao interrompê-la, residem todos os mais

\footnotetext{
${ }^{15}$ Cfr. ibid., p. 113.

${ }^{16}$ Cfr. ibid., p. 83.
} 
profundos retratos de Rembrandt: a morte." ${ }^{17}$ Ora, uma afirmação deste género é difícil de demonstrar ou comprovar. Apenas podemos sugerir um consentimento passageiro. Segundo Simmel, o momento da morte está contido em tudo o que vive, e o auto-retrato, como Rembrandt demonstra, torna-a palpável na imagem do homem pintado ${ }^{18}$.

A morte existe de antemão na vida, apesar de a sua visibilidade só ser alcançada naquele momento único, que é o futuro. Apesar de tudo, somos seres mortais. Mas este destino não é externo, apesar de o designarmos como algo que irá acontecer irremediavelmente, ele mantém-se constante e presente a todo o momento, é "a coloração e a configuração da vida, sem a qual a nossa vida se converteria em algo impensável." 19

Temos a tendência para considerar a morte como uma violência que nos ameaça de fora da vida, como um destino que nos espera nalgum ponto da nossa vida. Encaramos a morte como a manifestação de um poder que não só está desligado da vida como está acima da própria vida. No entanto, ela não está fora da vida. Pelo contrário é um elemento da vida que é sentido com a vida e na vida. A morte está em nós "desde o nosso primeiro dia, não como uma possibilidade abstracta que chegará a realizar-se um dia, mas sim como a simples e concreta consistência da nossa vida" ${ }^{20}$.

Para reforçar a ideia desta presença na nossa vida, Simmel recorre à ordenação em pares opostos de muitas das determinações essenciais da nossa existência. Assim muitos conceitos encontram o seu sentido, limite e forma na correlação com o seu oposto: o bem e o mal, o feminino e o masculino e outros. A relação destes opostos no seu sentido relativo faz com que se excluam mutuamente. Porém, estas relações são por vezes englobadas num sentido absoluto, como é o caso da nossa existência. Então, apesar de a vida e a morte como opostos se excluírem em termos físicos e lógicos no seu sentido relativo, quando compreendidos por um sentido absoluto, isto é, pela vida, os seus limites são reciprocamente condicionados e podemos falar na "imanência da morte na vida" ${ }^{21}$. E esta é demonstrada nos retratos e auto-retratos de um modo singular sobretudo quando evitam certas concepções herdadas desde a antiguidade clássica. Ora, o caminho que a arte clássica elege é em parte a procura da Ideia. Não lhe interessa o fenómeno singular ou a individualidade que flui no tempo. Ela procura uma lógica que está subtraída a todo o tempo e a toda

\footnotetext{
${ }^{17}$ Ibid., p. 119.

${ }^{18}$ Cfr. Jean Luc Nancy, Le Regard du Portrait, Paris, Galilée, 2000, p. 54.

${ }^{19}$ Georg Simmel, op. cit., p. 121.

20 Ibid., p. 122.

${ }^{21}$ Ibid., p. 123.
} 
a individualidade. A configuração do singular é construída a partir de uma legitimidade universal da forma. Isto é, o indivíduo não é visto na sua singularidade mas como exemplo de uma existência universal, daí que o retrato clássico seja a representação do supra-individual ${ }^{22}$. Este modo de olhar o retrato reflecte a influência da teoria da Ideia de Platão, quando coloca as coisas como representantes da Ideia, pois sem esta elas não teriam sequer existência. Assim, as coisas só demonstrariam interesse se fossem um modo de traduzir a presença do universal na forma sensível, já que "a Ideia pode ser representada por muitas coisas singulares, tal como um papel por muitos actores." 23

Por conseguinte, deste modo existe um afastamento da pura individualidade, da vida que anima o individual, pois não se representa na corrente da vida, não se capta desde dentro da sua estrutura singular, mas sim na sua fixa forma que é reflexo de uma ordem superior. Sem o movimento que a própria plenitude da vida confere ao encher por dentro a forma no seu constante fluir, cujo desenrolar é a aproximação da morte, pois quando a vida é sentida enquanto vida, a morte está presente. Sem esta vitalidade os retratos clássicos procuram representar aquilo que é fundamental para a Ideia. Isto é, aquilo que não muda e que é eterno. Então, torna-se difícil incluir neles a morte, pois a pessoa não está representada na sua singularidade mas no seu ser supra-individual que reflecte a forma intencional da natureza que é eterna em si. Recusa assim a sua materialidade e a contingência da sua realidade sensível.

Contudo não podemos dizer que em retrato algum a morte não está presente, pois ela acaba sempre por estar com maior ou menor intensidade, desde que se trate do retrato de alguém independentemente de estar ainda vivo ou já morto. A morte está apenas oferecida como conteúdo na sua intemporalidade. Portanto, o retrato clássico não estabelece a oposição entre a temporalidade do ser mortal e a intemporalidade da sua configuração plástica. Pelo contrário, o objecto é elevado em todas as suas qualidades e significações à esfera da intemporalidade. E isto é possível exactamente porque o retrato clássico está convertido a um tipo que, como é eterno, não morre e por essa razão imortaliza ou exclui a presença da morte no retrato.

Em Rembrandt encontramos de um modo exemplar o contrário do que acima dissemos em relação ao retrato clássico. De facto, nos seus retratos está presente o assumir da individualidade absoluta do retratado. $\mathrm{O}$ retratado enquanto indivíduo faz-nos sentir mais perto da sua morte, porque como simples indivíduo a morte está presente. Assim, quanto mais o retrato consegue trazer a ideia de individualidade, tanto mais mor-

${ }^{22}$ Cfr. ibid., p. 124.

23 Ibid., p. 125. 
tal ele se torna. Visto que o singular é insubstituível e o seu desaparecimento será tanto mais definitivo quanto mais singular for. Portanto, quanto mais profunda for a individualidade, mais nela está enraizada a fatalidade da morte.

A experiência do auto-retrato apresenta como meio de identificação diversas atitudes que questionam a ideia de rosto tanto no que ela tem de invisível como de visível sem abordar directamente os momentos vividos. E estes momentos são importantes porque distinguem em grande parte a característica do retratar que coincide desde sempre com o problema da sua duração. De facto, na obra de Édouard Pommier é referido este problema que se apresenta ao artista como algo que tem tanto de tormentoso como de cómico. Isto é, no desejo de dar à representação a verdade total do modelo, as sessões de pose são multiplicadas. Porém, a transformação que o modelo sofre de instante em instante e de dia para dia torna impossível esse realismo. O problema parece residir na impossibilidade de conseguir parar o tempo ${ }^{24}$. Assim, esta abordagem, com base na obra de Simmel sobre Rembrandt, abre a experiência do auto-retrato ao encontro da vida não só do nosso quotidiano como ao longo dela, ao usar esse problema como tema fundamental do retrato. No entanto, é de salientar que falamos de Rembrandt apenas como um exemplo ao qual se seguem muitos outros embora, obviamente, com diferentes respostas estéticas consonantes com o desenrolar da arte nos últimos séculos. Indicamos então, a título de curiosidade, os nomes de Van Gogh, Jacek Malczewski, De Chirico e Stanley Spencer.

Todos eles, como Rembrandt, demonstram a possibilidade de o retrato poder apresentar uma forma que é actual nos momentos da sua execução, mas não é final, pois nunca se pode dizer que o retrato está acabado. Porque eles são feitos do resultado de uma soma de observações que se efectuam durante o tempo da construção pictórica. Portanto, a questão reside na necessidade de procurar a forma a partir da vida e dos seus instantes que trazem consigo toda a vida do retratado. Isto é, a forma dá-se na vida e numa corrente que passa por ela através das suas relações com o tempo e com a força que permite ao corpo revelar-se. O retrato capta, assim, o instante vibrante animado por uma força que transporta a vitalidade do homem. Por sua vez, a sequência de retratos executados ao longo da vida, torna mais perceptível essa vitalidade ao mostrar as suas variações. Nesta aproximação tão íntima ao indivíduo, a construção do auto-retrato é feita a 'partir de dentro', recusando o aperfeiçoamento ou as normas como se tratasse do nascer de uma forma que nunca logrará ver-se acabada. Este 'a partir de dentro' é caro ao auto-retrato, pois é o único

${ }^{24}$ Cfr. Édouard Pommier, Théories du Portrait, De la Renaissance aux Lumières, Paris, Gallimard, 1998, p. 46. 
género de pintura em que o corpo e a alma não estão separados. Então, ao procurar o singular e o particular de si, talvez se consiga desse modo transmitir aquilo que ele tem de único e que dá unidade à existência, isto é, a sua individualidade. E quanto maior for a caracterização da individualidade enquanto registo de uma existência, mais presente nela está a morte e quando ao longo da vida ela se fizer mais presente nos diversos auto-retratos, então mais consciência temos de toda a nossa vida.

\title{
RESUMO
}

Partindo da obra de Georg Simmel sobre Rembrandt procura-se caracterizar o auto-retrato como um momento íntimo de confronto e de pesquisa sobre a nossa interioridade e individualidade. O carácter efémero da vida, onde é constante a presença da morte, está por excelência presente em todo o auto-retrato. Este nasce pelo desenho que o desenvolve numa continuidade onde o passado se projecta no presente. $\mathrm{O}$ rosto é a soma de uma duração que molda a fisionomia, a expressão e a variação numa tensão que traz para o presente o passado que se refaz num agora. Assim, o auto-retrato, mais do que o retrato, encerra em si a possibilidade de transmitir aquilo que o sujeito tem de único e distinto enquanto indivíduo. Neste sentido, o auto-retrato representa o conhecimento de uma individualidade sentida no próprio processo da vida, tomada da corrente da vida e na unidade da sua existência.

Palavras-chave: auto-retrato, individualidade, duração, vida, morte

\begin{abstract}
Departing from the work of Georg Simmel on Rembrandt, we try to characterize self-portrait as a moment of inner confrontation and of inner inquiry on our inner self and individuality. All self-portraits are pervaded by the ephemeral character of life, where death is constantly present. The self-portrait is born from the drawing and the drawing develops it in a continuity where the past juts out in the present. The human face is the sum of a duration that moulds its traits, its expression and its variation in a tension that brings the past to a present that is now remade.Thus, the self-portrait, more than the portrait, enables the possibility to transmit what the subject has of unique as an individual. In this sense, the self-portrait represents the knowledge of an individuality felt in the process of life, individuality withdrawn from the stream of life and in the unity of its existence.
\end{abstract}

Keywords: self-portrait, individuality, duration, life, death 